\title{
Preparation and Antimicrobial Activity of Antimicrobial Peptides from Plum Deer Antler
}

\author{
BO Shi-ru ${ }^{1}$, YU Jiang-hua ${ }^{1}$, Wang Ya-li ${ }^{1}$, WANG Quan-kai ${ }^{2}$ \\ ${ }^{1}$ Jilin Agricultural Science and Technology College, Jilin 132101, China \\ ${ }^{2}$ Jilin Agricultural University, Changchun 130000, China
}

Keywords: sika deer antler, collagen polypeptide, antibacterial

\begin{abstract}
The optimum conditions for the enzymolysis were as follows: temperature $50{ }^{\circ} \mathrm{C}, \mathrm{pH} 6.0$, time of hydrolysis $5 \mathrm{~h}$, the optimum conditions were as follows: temperature $50{ }^{\circ} \mathrm{C}, \mathrm{pH} 6.0$, The amount of enzyme was $6000 \mathrm{U} / \mathrm{g}$, and the degree of hydrolysis of the collagen deer velvet collagen was $15.49 \%$. The molecular weight of the collagen peptides was determined to be below $6.5 \mathrm{kD}$ by SDS-PAGE gel electrophoresis, and then the collagen peptide. The results showed that the obtained small molecule collagen peptide had good antibacterial activity against Escherichia coli and the inhibitory rate was $83.33 \%$ and $69.23 \%$.by Sephadex G-25 column gel chromatography.
\end{abstract}

\section{Introduction}

At present, bacterial infection and bacterial disease is on the rise, the formation of bacterial resistance is an important reason. The emergence of drug-resistant bacteria caused by the existing antibacterial drugs on bacterial infection treatment ineffective or ineffective, the formation of increasingly serious harm, how to overcome the bacterial resistance is the current research focus and hot spots. Therefore, there is an urgent need to develop new antibacterial agents. Collagen peptides are hydrolysates of collagen, is a variety of biological cells specific genes encoded by the external conditions induced by a class of broad-spectrum antibacterial bacteria, fungi, viruses, protozoa, kill tumor cells and other active effects of the polypeptide. Efficient, low toxicity, broad-spectrum antimicrobial peptides as the most promising alternative to antibiotics, new pharmaceutical preparations much attention at home and abroad researchers, become the current research focus, however, there are no reports on the preparation of collagen peptides from traditional Chinese medicine sika deer antler.

\section{Experimental Materials}

Main Raw Materials and Reagents. Sika deer antler collagen (laboratory homemade) dialysis bag (Changchun aoke Biological Technology Ltd), SephadexG-25 (Changchun aoke Biological Technology Ltd), Bacteria counting plate(Changchun aoke Biological Technology Ltd),Columns, Sterile filter (Changchun aoke Biological Technology Ltd). Papain (80 million U/g) Guangzhou Zhongyuan Biotechnology Co., Ltd. (Food grade), Other reagents for the laboratory commonly used reagents.

Main Equipment. UV-visible spectrophotometer(Shimadzu Corporation), Constant temperature incubator(Shanghai and was equipment Manufacturing Co., Ltd), Optical microscope(Shanghai Unity Instrument Manufacturing Co, Ltd).

\section{Experimental Method}

Preparation of Paraffin Polypeptide Form. The pre - vacuum freeze - dried preparation of sika deer antler powder as raw material, to the degree of hydrolysis as an indicator, at a substrate concentration of $6 \%$, using single factor and orthogonal test, the optimum factors for the hydrolysis of papain were determined by the amount of enzyme, the reaction time, the reaction temperature and the $\mathrm{pH}$ value of the papaya antler collagen. 
Determination of Degree of Hydrolysis $(\mathbf{D H})$. The degree of hydrolysis was determined by the PH-Start method [1], by recording the volume of lye consumption, Calculate the degree of hydrolysis.

The formula is: $\mathrm{DH}(\%)=\frac{\mathrm{B} \times \mathrm{N}}{\alpha \times \mathrm{b} \times \mathrm{h}} \times 100 \%$

Where $B$ : consumption of alkali $(\mathrm{mL}) ; N$ : NaOH molar concentration(mol/L); $M$ : Substrate protein quality (g); $H$ : $8.41 \mathrm{mmol} / \mathrm{g} ; \alpha$ : average dissociation of amino groups.

The formula of $\alpha$ is: $\alpha=\frac{10^{P H-P K}}{1+10^{P H-P K}}$

Effect of Enzyme Dosage on Degree of Hydrolysis. PH 6.0 was adjusted with $2 \mathrm{~mol} / \mathrm{L}$ HCL, reaction $4 \mathrm{~h}$, hydrolysis temperature $50{ }^{\circ} \mathrm{C}$ for the fixed conditions, the amount of enzyme added was $4000 \mathrm{U} / \mathrm{g}, 6000 \mathrm{U} / \mathrm{g}, 8000 \mathrm{U} / \mathrm{g}, 10000 \mathrm{U} / \mathrm{g}, 12000 \mathrm{U} / \mathrm{g}$ for enzymatic extraction, to the degree of hydrolysis as an indicator, the effect of enzymatic hydrolysis on the yield was determined.

Effect of Hydrolysis Time on Degree of Hydrolysis. PH 6.0 was adjusted with $2 \mathrm{~mol} / \mathrm{L}$ HCL, add $80 \mathrm{U} / \mathrm{mg}$ papain, hydrolysis temperature $50{ }^{\circ} \mathrm{C}$ for the fixed conditions, respectively, hydrolysis $1 \mathrm{~h}, 2 \mathrm{~h}, 3 \mathrm{~h}, 4 \mathrm{~h}, 5 \mathrm{~h}$, enzymatic extraction, to the degree of hydrolysis as an indicator, the effect of enzymatic hydrolysis on the yield was determined.

The Effect of Temperature on the Degree of Hydrolysis. PH 6.0 was adjusted with $2 \mathrm{~mol} / \mathrm{L}$ $\mathrm{HCL}$, add $80 \mathrm{U} / \mathrm{mg}$ papain, reaction $4 \mathrm{~h}$ for the fixed conditions. Respectively, at $30{ }^{\circ} \mathrm{C}, 40{ }^{\circ} \mathrm{C}$, $50{ }^{\circ} \mathrm{C}, 60{ }^{\circ} \mathrm{C}$ for enzymatic extraction, to the degree of hydrolysis as an indicator, the effect of enzymatic hydrolysis on the yield was determined.

The Effect of PH on the Degree of Hydrolysis. The hydrolysis time was 4 h for the dosage of $8000 \mathrm{U} / \mathrm{g}$ and the hydrolysis temperature was $50{ }^{\circ} \mathrm{C}$, Respectively, change the $\mathrm{pH}$ of the hydrolyzate to $4.0,5.0,6.0,7.0,8.0$, enzymatic extraction, to the degree of hydrolysis as an indicator, the effect of enzymatic hydrolysis on the yield was determined.

Orthogonal Test. The degree of hydrolysis of collagen deer velvet collagen was taken as an index, to determine the optimum hydrolysis conditions, L9 $\left(3^{4}\right)$ orthogonal test design see Table 1.

Table 1 Antler papain extracted collagen polypeptide factor level table

\begin{tabular}{c|cccc}
\hline Fevel & Temperature $\left({ }^{\circ} \mathrm{C}\right)$ & $\mathrm{PH}$ & Time $(\mathrm{h})$ & $\begin{array}{c}\text { Enzyme dosag } \\
(\mathrm{U} / \mathrm{g})\end{array}$ \\
\hline 1 & 40 & 5 & 3 & 6000 \\
2 & 50 & 6 & 4 & 8000 \\
3 & 60 & 7 & 5 & 10000 \\
\hline
\end{tabular}

Isolation and Purification of Collagen. Sephadex G-25 Gel Chromatography. Pretreatment. Weigh Sephadex G-25 (100 mesh) about 5g, add distilled water to 100ml, at room temperature for 3h to swell.

Packed column. First add 1/3 column volume of distilled water, then, the swollen gel is stirred and continuously loaded. At the same time open the mouth slowly out of distilled water, after being installed, equilibrated with distilled water for 2-3h.

Add sample. The excess gel in the column above the discharge of distilled water, until the liquid level inside the column coincides with the gel surface. Add $2 \mathrm{ml}$ of hydrolyzate, after adding the sample, open the mouth slowly release the liquid to the liquid surface and gel surface, and then use a small amount of distilled water to rinse the original sample container 2-3 times, until all the column into the column, waiting for elution.

Elution and collection. Use distilled water as eluent, and to continue to continue, so that the top of the gel column to maintain a certain liquid layer, prevents liquid on the surface of the gel column. The rate of elution of the eluent should be controlled at $1.0 \mathrm{ml} / \mathrm{min}$. Collected in succession, each tube to collect $4 \mathrm{ml}$, a total of 10 tubes were collected, ultraviolet detection of A220nm, Determining the polypeptide concentration maximum tube No. $4,4{ }^{\circ} \mathrm{C}$ refrigerator to save spare. 
Concentrated Polypeptide. Take the separation solution in a small beaker, and dried in vacuo at $25{ }^{\circ} \mathrm{C}$ with an empty drier. The powder was collected and dried in refrigerator at $4{ }^{\circ} \mathrm{C}$ standby.

Antler Determination of Collagen and Collagen Polypeptide Molecular Weight. SDS-PAGE gel electrophoresis method was used to determine the method, according to the literature [2], separating gel concentration of $10 \%$ and concentrated gel concentration of $5 \%$, concentrated gel voltage is $70 \mathrm{mv}$, separation gel voltage $140 \mathrm{mv}$. After $4 \mathrm{~h}$ of dyeing, decolorization was carried out with decolorization solution (methanol: glacial acetic acid: water $=4.5: 4.5:$ l), until the background is clear.

Determination of Antibacterial Activity of the Original Polypeptide of Deer Antler. Preparation of Bacterial Culture Medium. Take beef extract $5.0 \mathrm{~g}, \mathrm{NaCl} 5.0 \mathrm{~g}$, agar 25g, water $1000 \mathrm{ml}$, the yeast extract or beef extract, sodium chloride and water mixed was dissolved by heating, measured and corrected $\mathrm{PH} 7.2$ to 7.4 , filter boiled fully melted, $121.3{ }^{\circ} \mathrm{C}$ high pressure steam sterilization $15 \mathrm{~min}$.

Preparation of Drug Sensitive Tablets. The plurality of sheets susceptibility test group placed polypeptide was immersed 12 hours, the control group was placed in physiological saline for 12 hours. After soaking, the drug sensitive tablets are removed from the infusion and dried naturally, spare.

Drug Sensitivity Patch Test. The solid with a good culture medium after sterilization was poured into hot more sterile petri dish, after waiting for solidification, respectively connected Staphylococcus aureus and Escherichia coli, apply evenly with coated sticks. Under sterile operating conditions were attached to each dish and the test group and control group susceptibility sheet. The culture dishes were then incubated in a constant temperature incubator at $37{ }^{\circ} \mathrm{C}$ for 12 hours to observe the results.

Antibacterial Test of Collagen Peptide Solution. Set the control group and test group, test group in the $1.5 \mathrm{ml}$ centrifuge tube plus $700 \mathrm{ml}$ culture medium, $200 \mathrm{ml}$ peptide solution plus $150 \mathrm{ml}$ bacteria solution, The control group in the $1.5 \mathrm{ml}$ centrifuge tube plus $700 \mathrm{ml}$ culture medium, $200 \mathrm{ml}$ normal saline plus $150 \mathrm{ml}$ bacteria, the bacteria is diluted 100 times. The two groups were incubated in a constant temperature incubator for 12 hours. And then counted on the micro-counting plate, respectively. Calculate the inhibitory rate.

\section{Results and Analysis}

Preparation of Sika Deer Antler Collagen Peptide. Effect of Enzyme Amount on Enzymatic Hydrolysis. The effect of papain on the degree of hydrolysis is not obvious, when the amount of enzyme more than $8000 \mathrm{U} / \mathrm{g}$, the degree of increase in the degree of hydrolysis no longer significant changes, continue to increase the degree of hydrolysis of the enzyme has been very little, but will increase the cost of the trial. Therefore, the final determination of the antler antler collagen protein hydrolysis of the best suitable range of 6000 10000U/g.

Effect of PH Value on Enzymatic Hydrolysis. When the $\mathrm{pH}$ value increases from 4.0 to 6.0, the degree of hydrolysis increases gradually; When the $\mathrm{pH}$ increased from 8.0 to 6.0, the degree of hydrolysis decreased, that is, when the curve inflection point pH6.0, the highest degree of hydrolysis. Therefore, the optimum $\mathrm{pH}$ of the papain hydrolyzate Xikalu antler collagen is 5.0 to 7.0.

Effect of Temperature on Enzymatic Hydrolysis. With the increase of temperature, the degree of hydrolysis increased first and then decreased, and the degree of hydrolysis reached the highest level at $50{ }^{\circ} \mathrm{C}$, which was consistent with the optimum reaction temperature of papain reported in the literature. The reason for the decrease in the degree of hydrolysis after the temperature exceeds $50^{\circ} \mathrm{C}$ may be due to the fact that the temperature is too high leading to papain inactivation. Therefore, the best temperature range of $40 \sim 60{ }^{\circ} \mathrm{C}$, the final determination of the original protein hydrolysis papaya melon antler.

Effect of Time on Enzymatic Hydrolysis. With the extension of reaction time, the degree of hydrolysis gradually increased. When the reaction time exceeds $4 \mathrm{~h}$, the degree of hydrolysis is constant with time, and the increase of hydrolysis time may affect the hydrolysis efficiency and 
extraction efficiency. Therefore, the optimal time for the final selection of papain hydrolyzate of sika deer antler collagen is 3 to $5 \mathrm{~h}$.

Determination of Optimum Hydrolysis Conditions of Papain. The L9 $\left(3^{4}\right)$ orthogonal test was conducted on a single factor basis. The results showed that the temperature, $\mathrm{pH}$ value, reaction time and enzyme dosage of papain were analyzed by orthogonal test, the results are shown in Table 2 and Table 3.

Table 2 Papain Hydrolysis Orthogonal Test Results

\begin{tabular}{cccccc}
\hline Number & Temperature & PH & Time & Enzyme dosage & Degree of hydrolysis(DH\%) \\
\hline 1 & 1 & 1 & 1 & 1 & 13.31 \\
2 & 1 & 2 & 2 & 2 & 14.42 \\
3 & 1 & 3 & 3 & 3 & 14.01 \\
4 & 2 & 1 & 2 & 3 & 15.32 \\
5 & 2 & 2 & 3 & 1 & 15.57 \\
6 & 2 & 3 & 1 & 2 & 14.06 \\
7 & 3 & 1 & 3 & 2 & 13.85 \\
8 & 3 & 2 & 1 & 3 & 14.42 \\
9 & 3 & 3 & 2 & 1 & 13.83 \\
\hline $\mathrm{K} 1$ & 41.74 & 42.48 & 44.79 & 46.21 & \\
$\mathrm{~K} 2$ & 46.45 & 48.91 & 43.57 & 42.33 & \\
$\mathrm{~K} 3$ & 45.10 & 41.90 & 44.93 & 44.75 & \\
\hline $\mathrm{k}_{1}$ & 13.91 & 14.16 & 14.93 & 15.74 & \\
$\mathrm{k}_{2}$ & 15.48 & 16.30 & 14.52 & 14.11 & \\
$\mathrm{k}_{3}$ & 15.03 & 13.97 & 14.98 & 14.58 & \\
\hline $\mathrm{R}$ & 1.57 & 2.34 & 0.45 & 1.47 & \\
\hline
\end{tabular}

Table 3 Analysis of variance tables

\begin{tabular}{cccccc}
\hline Source of variance & $\begin{array}{c}\text { Deviation } \\
\text { side and }\end{array}$ & $\begin{array}{c}\text { Degrees of } \\
\text { freedom }\end{array}$ & variance & F value & Significance \\
\hline A & 3.92 & 2 & 1.96 & 10.52 & $\mathrm{P}<0.1$ \\
B & 10.09 & 2 & 5.05 & 27.06 & $\mathrm{P}<0.05$ \\
C & 0.37 & 2 & 1.90 & 1.00 & $\mathrm{P}>0.1$ \\
D & 3.28 & 2 & 1.64 & 8.80 & $\mathrm{P}>0.1$ \\
\hline
\end{tabular}

$\mathrm{F}_{0.1(2,2)}=9.00 \quad \mathrm{~F}_{0.05(2,2)}=19.00 \quad \mathrm{~F}_{0.01(2,2)}=99$

Using intuitive analysis we can see, the degree of hydrolysis is the index, major and minor factors $\mathrm{B}>\mathrm{A}>\mathrm{D}>\mathrm{C}$, ie $\mathrm{pH}>$ enzyme hydrolysis $>$ enzyme $>$ enzyme release time; The variance analysis results show that: $\mathrm{B}$ factors having significant $(\mathrm{P}<0.05)$, A factor having a significant $(\mathrm{P}$ $<0.1$ ) , comprehensive analysis of the results of differences, combined with the best $A_{2} B_{2} C_{3} D_{1}$; That is, the temperature is $50{ }^{\circ} \mathrm{C}$, the $\mathrm{pH}$ value is 6.0 , the reaction time is 5 , the optimum enzyme dosage is $6000 \mathrm{U} / \mathrm{g}$. The experimental results show that the extraction of $\mathrm{A}_{2} \mathrm{~B}_{2} \mathrm{C}_{3} \mathrm{D}_{1}$ is feasible in the optimization experiment, and the degree of hydrolysis of the hydrolyzed collagen polypeptide is $15.59 \%$. 


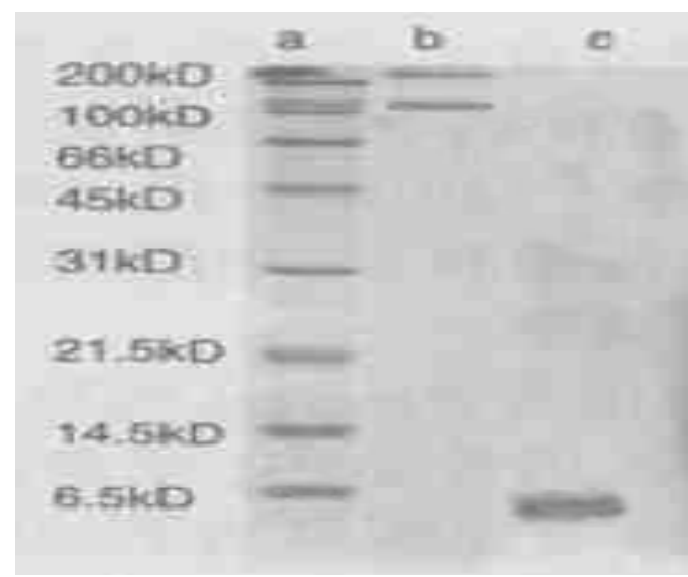

a- Protein Marker; b-sika deer antler collagen; c-sika deer antler collagen peptide Fig.1 Sika Deer Velvet collagen and collagen peptides electrophoresis

As can be seen from Figure 1, sika deer antler collagen protein molecular weight between $100 \mathrm{kD}-200 \mathrm{kD}$, is a macromolecule material, molecular weight distribution range is narrow, indicating that deer antler collagen to maintain a complete three-strand spiral structure. Sika deer antler collagen peptide concentration concentration below $6.5 \mathrm{kD}$, molecular weight can be seen, antler collagen has been papain digestion into small molecules digestion and absorption.

Antler Collagen Polypeptide Determination of Antibacterial Activity. As can be seen from Figure 2, the experimental preparation of the antler collagen peptide on E. coli and Staphylococcus aureus have inhibitory effect, the inhibitory effect is significant.

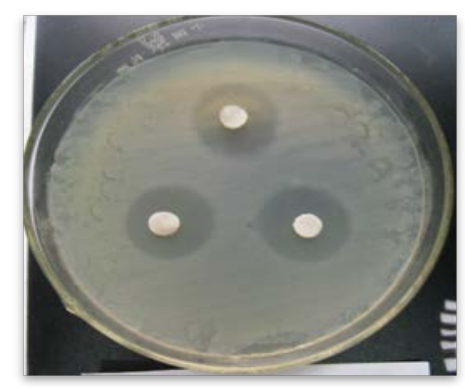

(a)Escherichia coli

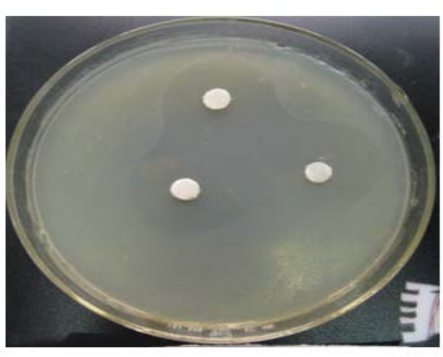

(b)Staphylococcus aureus

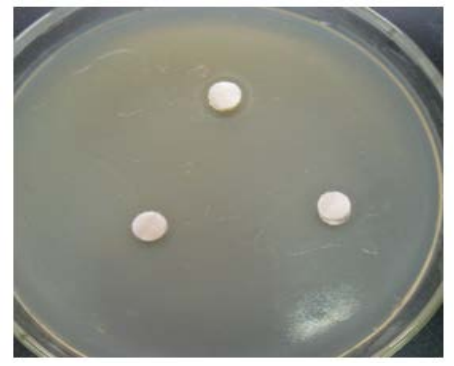

(c)Control group

Fig.2 Drug susceptibility test results

Antibacterial Count. Inhibition rate $/ \%=(\mathrm{N}($ control $)-\mathrm{N}($ test $)) / \mathrm{N}($ control $) \times 100 \%$ [3] (In the formula: Control $\mathrm{N}$ is the number of bacterial bacteria in the control tube; Experiment $\mathrm{N}$ is the total number of bacterial colonies for the experimental tubes.) As can be seen from Table 4, the antibacterial rate of Escherichia coli was 83.33\%, and the inhibition rate of Staphylococcus aureus was $69.23 \%$.

Table 4 Antibacterial count results

\begin{tabular}{ccccccccc}
\hline Group & 1 & 2 & 3 & 4 & 5 & 6 & 7 & average \\
\hline Test group & 6 & 7 & 6 & 5 & 2 & 4 & 10 & 5 \\
\hline Test group & 8 & 11 & 12 & 7 & 9 & 7 & 11 & 9 \\
\hline The control group & 9 & 12 & 17 & 18 & 11 & 10 & 12 & 13 \\
\hline
\end{tabular}

\section{Conclusion}

From the experimental results can be seen, plum deer antler's collagen has a certain antibacterial activity. Antimicrobial susceptibility test showed that plum deer Antler collagen on the inhibition of E. coli stronger than Staphylococcus aureus. The inhibitory rate of Escherichia coli was 83.33\%, the inhibition rate of Staphylococcus aureus was 69.23\%, indicating that the plum deer antler collagen peptide has obvious antibacterial effect, wherein the intensity inhibit Escherichia coli, 
staphylococcus aureus is relatively weak inhibition, the isolated polypeptide may also inhibit other strains, further study. If the plum deer antler's collagen peptide as an antibacterial drug development, animal experiments also need to verify its practical role.

\section{References}

[1]Adleb Nissen J.Enzymatic hydrolysis of food Peoteins. London: Elsevier Applied Science Publishers, 1986:12-14.

[2] Zhang Longxiang, Zhang Tingfang, Li Lingyuan, etc. Biochemical experimental methods and techniques [M]. Beijing: People's Education Press, 1991.112-118.

[3] Zhang Shunliang, Pan Xiaoqian, Cheng Xiaoyu, Qiao Xiaoling, etc. And analysis of the components of separation and purification of bovine collagen source of antibacterial peptide[J]. Meat research, 2013, (11): 33-36. 